\title{
La medicina, una ciencia y un arte humanos
}

\author{
J.A. Gutiérrez-Fuentes
}

'No importa qué, sino cómo lo sufras'

Séneca

Ante la realidad del sufrimiento, el ser humano ha reaccionado y adoptado actitudes que le permitiesen conocer y comprender el fenómeno, y situarse ante el mismo. En buena parte, la armonización de dichos conocimientos y las actuaciones que de ellos se han generado forman el sustrato de la medicina.

Es conveniente hacer un poco de historia, así como un análisis desde perspectivas diferentes -antropológica, filosófica y social- para tratar de entender cómo enfrentamos hoy estas realidades.

En la antigua Grecia, Sócrates, Platón o Jenofonte utilizaban la palabra fronesis para expresar 'espíritu, mente, inteligencia, conocimiento, sabiduría, nobleza, magnanimidad, propósito, buen juicio, temple, ánimo, confianza en sí mismo', etc. A lo largo del s. v a.C., el concepto extiende su campo semántico a determinadas capacidades como el conocimiento del valor y del bien, el espíritu animoso, conocer los bienes supremos, conocer la causa última de las cosas y del universo. Pero a partir de Aristóteles, aun conservando la polisemia anterior, fronesis se refiere cada vez más, no tanto a la vida contemplativa y a la comprensión teórica, sino a la vida activa y al entendimiento práctico, al mundo de las elecciones cotidianas, para las que se hace necesario poseer 'buen juicio, temple, confianza en sí mismo para saber elegir aquello que resulte más conveniente' para activar o mantener la felicidad.

Ya entre los romanos, la fronesis se traslada al campo semántico de la pro-videntia (cuida- do, cautela, previsión, provisión). Este último sustantivo se contrae en la forma prudentia, que en el lenguaje de Cicerón y de los juristas pasa a significar 'inteligencia práctica, ingenio, conocimiento'. Entre los 'prudentes', el derecho deja de ser imperativo inflexible del orden público, la regla impuesta y absoluta; su fundamento no es ya la autoridad, sino la razón práctica, atenida a la 'naturaleza de la cosa'.

Desde entonces, la 'prudencia' alude a la previsión racional, es la virtud de actuar de forma justa, adecuada y con cautela, resultante de la inferencia o deducción basadas en la noticia del pasado, en el saber recibido de los 'prudentes' y en el conocimiento de las circunstancias del presente, pero sin quedarse en el conocimiento, pues debe llevar a elegir y a imperar la acción.

Tomás de Aquino da centralidad a la 'providencia' o 'prudencia', que une racionalidad y actualidad circunstancial. Está convencido de que, a pesar de que el hombre puede 'hacerse todas las cosas' por medio de su inteligencia, el dominio de la realidad al que accede, por su limitación y finitud, es un dominio inestable y mudable. Precisamente el dinamismo de la 'prudencia' consiste en 'ver y prever a través de la incertidumbre', como sostiene citando a San Isidoro de Sevilla (Etymol): 'Prudente significa cómo ver a lo lejos; es ciertamente perspicaz y prevé a través de la incertidumbre de los sucesos'. En definitiva, la 'prudencia' se construye sobre el conocimiento a través de la memoria, la inteligencia y la razón de las vivencias del pasado, y se pone en práctica con los fines y medios adecuados en cada caso y momento, para la mejor elección y ejecución de una acción determinada.
Director de la Fundación Lilly. Madrid, España.

E-mail j_a_gutierrez@lilly.com 
Pero si alcanzar la prudencia fue la meta de la educación durante la Edad Media, después del Renacimiento su ensamblaje se distorsionó y algunos aspectos alcanzaron gradualmente especial preponderancia. Diferentes intelectuales, desde Maquiavelo (1469-1527) hasta Gracián (16011658), en su Oráculo manual y arte de prudencia, colaboran para que la prudencia se entienda más como astucia, cautela, simulación y dolo para no comprometerse en ninguna situación. Así, la audacia creativa y responsable en situación se ve sustituida por la habilidad para evitar las responsabilidades, escurrir el bulto y no correr riesgos. Tanto es así, que Immanuel Kant (1724-1804) evita la prudencia en su 'ética', al considerarla mera habilidad pragmática para ejercer influjo sobre los otros, para utilizarlos conforme a los propios designios de bienestar privado.

La cuestión sigue candente hoy con la afloración de otras interpretaciones. Así, Fernando Savater (2003) en su libro El valor de elegir, en el que expresa su rechazo a los dogmas, propone una ética y una estética de la contingencia, en la que lo contingente -lo que puede suceder o noes parte del precio de la superación, en tanto trascendencia. A la pregunta ¿qué es lo que define al ser humano?, responde que 'no son los instintos o nuestra situación genética, tan semejantes a los de otros animales, sino nuestra capacidad de decidir e inventar acciones que transforman la realidad ... y a nosotros mismos'. A tal disposición no la llama precisamente prudencia -término desgastado y con muchas connotaciones que ya no dicen lo que era la fronesis ni la vieja 'prudencia' tomista-, sino simplemente 'libertad'.

Sin embargo, aunque es evidente que la carencia de libertad imposibilita el ejercicio de cualquier elección, incluso la prudente, la libertad sólo es factible si se dan las virtudes y circunstancias que caracterizan a la fronesis.

La ética, como disciplina que tiene por objeto el ethos integral, define la vocación humana de cada individuo dentro del conjunto. Ahora bien, sin perder de vista que cuando no se posea e impere la prudencia, integradora estable de todas las virtudes, faltará la predisposición al recto comportamiento en todas las ocasiones, así se equivocase el individuo innumerables veces.

En la ética clásica las normas elaboradas eran estables y se aplicaban en un mundo que las aceptaba y se sujetaba a éstas. Pero, en la actualidad, la ética se ha trasladado al desarrollo de la con- ciencia racional individual y al despliegue de una conciencia colectiva que pretende alcanzar el mejor juicio posible en casos y situaciones concretas. Esta ética no se plantea con base a ideales abstractos sino desde la experiencia adquirida de lo que somos y en la que transcurre nuestra existencia.

Sin embargo, esta concepción de la ética no siempre es fácil de llevar a la práctica. Al aceptar la ética como algo carente de referentes absolutos, encontramos en la situación de enfrentar, con una voluntad débil, ignorante y cambiante, la realidad del día a día, que no es buena ni mala sino compleja, confusa y ambivalente, como lo es la vida misma, y que nos devuelve a la reflexión moral. Sucede así con las actuaciones ante el enfermo, sobre todo cuando existe el dolor, el sufrimiento o ante el paciente terminal, en las que se ha de asumir e integrar, por un lado, la indeterminación, la duda, la 'incertidumbre' y, por otro, la deliberación juiciosa y fundamentada ante una situación concreta, compleja y variable. Hacerlo ante cada caso y circunstancia requiere de una capacidad juiciosa que podemos llamar arte o arte médico.

La ética educa para la libertad y el ejercicio de la autonomía que permite decidir qué es lo correcto, lo erróneo y lo que puede ser tolerado. Es después de la Segunda Guerra Mundial, que llevados de la mano del desarrollo y el avance de las ciencias médicas y de las tecnologías aplicadas a la medicina, empiezan a aparecer nuevos interrogantes: ¿cómo se define la vida de un ser humano?; ¿cómo se define la muerte?; ¿cuáles son las consecuencias del trasplante de órganos?; ¿ ¿cuáles las de las intervenciones y modificaciones sobre el genoma humano? En la búsqueda de las respuestas se afanan antropólogos, filósofos y teólogos, juristas y sociólogos, médicos y científicos, y del esfuerzo prolongado comienzan a emanar ideas y propuestas que modifican las centenarias formas éticas que habían modulado la relación entre médicos y pacientes.

En este ambiente, el oncólogo danés Van Rensselaer Potter utiliza por primera vez en 1970 el término 'bioética', con el que aludía a los problemas que el gran desarrollo de la tecnología plantea a un mundo en plena crisis de valores. La bioética surge, por tanto, como la 'ciencia de la supervivencia', la fórmula necesaria para restablecer un puente entre ambas esferas de conocimiento: la ciencia experimental y las humanidades. Se pretende así, a través de una deliberación interdisciplinar, 
la formulación de unos principios que permitan orientar y humanizar el quehacer científico para afrontar con responsabilidad las posibilidades enormes que hoy nos ofrece la tecnología. A partir de 1971 se da una nueva orientación al concepto de 'bioética' (André E. Hellegers), poniendo el énfasis en el estudio de los aspectos éticos implícitos en la práctica clínica, que llevaría a la actual definición de la Encyclopedia of Bioethics como 'el estudio sistemático de la conducta humana en el área de las ciencias de la vida y el cuidado de la salud, en tanto esta conducta se analiza a la luz de valores y principios morales'.

Desde entonces son muchos y notables los autores que dedican su atención a la bioética. Se llega así a plantearla (Daniel Callahan y Willard Gaylin; Hastings Center) como la disciplina que pretende regular la interacción entre el que posee el conocimiento y aquel al que se le ofrece y puede recibir la aplicación práctica del mismo, siempre orientada a ayudarle en la solución de los problemas que le aquejan. De ahí la importancia en la relación entre médico y enfermo, de que el paciente analice libremente y con plena autonomía (capacidad de pensar, decidir y actuar libre e independientemente), hasta donde su conocimiento se lo permita y aconseje, las implicaciones de los tratamientos propuestos, y participe con su familia y el médico en las decisiones. No dejan de ser los pacientes quienes corren los riesgos que surgen de la aplicación de una u otra prueba diagnóstica o tratamiento, y el médico el que se responsabiliza de su prescripción.

En este entorno, y en esta necesidad de saber qué hacer en cada momento, los médicos y las enfermeras desarrollan su actividad y asumen su responsabilidad ante el enfermo que sufre, en la mayoría de los casos, valiéndose de su experiencia y de una 'ética' que afortunadamente aún se mantiene bastante próxima a la fronesis de Aristóteles y a la sabiduría, a la prudencia y al sentido común de Tomás de Aquino. Y es partiendo de estas reflexiones que intento ver la medicina como una ciencia que para ser útil requiere del arte del médico para aproximarla al paciente. Arte entendido como un no al reduccionismo (en este caso científico) y al dogmatismo (de escuela), y un sí a la apertura a la singularidad de cada ser humano.

Ya desde los griegos la medicina es una techné (es decir, lo que los latinos tradujeron por ars, 'arte' o 'técnica'), no una episteme, porque trata de curar al enfermo singular, no sólo de averiguar verdades universales e indiscutibles (que es lo que los griegos entendían por ciencia).

$\mathrm{El}$ arte médico consiste tanto en la determinación de las causas 'científicas' de la dolencia como en la comprensión de la situación personal del y por el paciente, porque se entiende que la curación es un proceso en que éste deberá dialogar consigo mismo (se supone que es la naturaleza quien cura y en la naturaleza del hombre está comprenderse a sí mismo) y con los males que le afligen, acompañado y ayudado por la actuación del médico.

Sin duda, la medicina como hoy la vivimos se parece poco a la que podía haber hecho predecir la evolución histórica de los conceptos que van desde la fronesis hasta la bioética. Incluso en el corto lapso de tiempo de la vida profesional de algunos de los veteranos aquí presentes los cambios resultan asombrosos y, en muchos casos, desconcertantes. Como hace ya más de 20 años, advirtió Roy Porter [7], estamos de hecho ante una auténtica redefinición de la función del médico ('Yet as those expectations become unlimited, they are unfulfillable: medicine will have to redefine its limits even as it extends its capacities').

Las causas profundas de lo que sucede no se pueden reducir a un problema que afecte sólo a la medicina o a los médicos, y residen en un conflicto moral más amplio y más grave que afecta a la sociedad en su conjunto, a una sociedad que no sabe muy bien ni lo que quiere ni lo que está dispuesta a poner en juego para conseguirlo, pero que, de momento, coloca a los médicos en una situación de grave ambigüedad frente a los enfermos.

Pero, volvamos la vista al objeto de nuestra consideración, y preguntémonos ¿cuál es finalmente el objetivo del ejercicio de nuestra profesión? Es conocida la frase que dice: 'La medicina cura en una tercera parte de los casos, alivia en las dos terceras partes y consuela en todos los casos'. Pues bien, la pregunta sigue siendo pertinente y hoy podemos preguntarnos: ¿seríamos capaces de analizar cuál es el porcentaje de este aserto en el ejercicio de nuestra profesión?

A mediados del s. xv, Paracelso hizo la que es posiblemente la mejor definición humanística de la salud: 'El equilibrio del ser humano consigo mismo y con su medio ambiente. Si aceptamos esta definición, podríamos preguntarnos: ¿en el ejercicio de nuestra actividad como médicos procuro que mis pacientes lleguen a obtener el equilibrio al que se refiere Paracelso?, ¿cuál es 
pues nuestra misión como médicos?, ¿logramos, además de curar, el objetivo de transmitir consuelo y satisfacción consigo mismos a nuestros pacientes?

Resulta revelador recordar que al valorar la satisfacción de los pacientes ante la prestación sanitaria en diferentes países, se repite con contumacia el destacado aprecio por la labor de los médicos, y se valora en ellos de forma destacada su actitud (interés, amabilidad, etc.), por encima de otros adjetivos como la sabiduría, presencia, eficiencia, fama, prestancia, conocimientos o habilidad. Es ésta una enseñanza para meditar que nos dice que el paciente no acude a la consulta sólo en busca de la curación de su enfermedad; busca también, y de manera fundamental, alivio, consuelo, comprensión y apoyo.

Tal como afirmó Hipócrates, el ejercicio de la medicina se asimila al del arte: 'El oficio es duro y el arte difícil'. La medicina se basa en la ciencia, que tiene que probar y comprobar, que es fría, estricta y precisa, y no tiene sensaciones. El arte expresa emociones y sentimientos, es amplio y carece de límites. El científico debe ser exacto y seguro, sin derecho al titubeo; el artista, en cambio, se desenvuelve dentro de la amplitud, la condescendencia y confiere a su actuación un estilo. Existe una ciencia médica; sin embargo, la práctica médica, la aproximación del conocimiento científico al paciente, precisa del arte médico como el vehículo y el estilo necesario para su buena aplicación.

¿Cuál es, entonces, nuestro 'estado del arte' en el trabajo diario? ¿Acaso el sistema en el que nos desenvolvemos, que ha mutado al paciente en cliente y a la actuación médica en un 'bien de consumo', se ha constituido en un obstáculo para que nuestra ciencia médica no nos permita el arte? Ejercemos nuestra profesión encorsetados por el sistema de salud bajo cuyas directrices debemos practicar. Cabe preguntarse: ¿el sistema que ampara el trabajo médico hace que el arduo oficio al que se refería Hipócrates sea más difícil, hasta el punto de hacer imposible el ejercicio del arte?

En medicina, y desde el momento que se trata de la realización práctica del conocimiento que el hombre posee y aplica sobre sus pares, el acto médico trasciende la aplicación de información científica. Surge en él una dimensión interpersonal desde dónde se forja la atmósfera terapéutica, ingrediente fundamental para el logro de una medicina efectiva. Es precisamente en la gestación de dicha atmósfera dónde reside el componente artístico del acto médico.

Según los entendidos, el arte posee dos fines fundamentales: transmitir sentimientos y emociones, y despertar la magia interior. Ambos objetivos artísticos impregnan a diario la actividad médica asistencial.

La transmisión de sentimientos y emociones está presente cuando el médico logra a través de su actitud que el paciente perciba el afecto que éste le profesa y el interés que tiene en ayudarlo. Esta situación consolida la alianza médicopaciente, que facilita la confianza del enfermo y su adherencia a los consejos y las prescripciones de su terapeuta.

La magia surge cuando en la relación médicopaciente se reeditan a un nivel inconsciente, el pensamiento mágico y sus contenidos arquetípicos. El arquetipo que se despliega en dicha situación es el del héroe épico (paciente), la prueba que debe superar (enfermedad) y la ayuda que recibe por parte del demiurgo -maestro- auxiliador (médico). Desde esta magia, inconscientemente evocada, se sustentan sentimientos de fe y esperanza de superar la enfermedad; sentimientos que ayudan al paciente a transitar por el duro camino de conocer lo qué le sucede e intentar ponerle remedio.

La educación médica tradicional ha enfocado su énfasis en el desarrollo del conocimiento, las destrezas y actitudes, cuando en el mundo moderno no sólo se debe educar para la competitividad sino para la capacidad de adaptarse al cambio, de generar nuevo conocimiento y de mejorar continuamente nuestro desempeño. Si bien la medicina se ha definido como el 'arte y ciencia del diagnóstico y tratamiento de las enfermedades y el mantenimiento de la salud', o también como 'el arte de prevenir o curar la enfermedad', para algunos la medicina moderna no es ni 'el arte de algo' ni ninguna ciencia, sino un agregado de artes y/o disciplinas. Es en este contexto que la educación médica debe tener muy bien definidos sus metas y procesos para lograr hacer de los estudiantes personas con la capacidad de practicar la medicina. Se trata de lograr que el aprendizaje no sea sólo una transmisión de hechos y contenidos, sino más bien un proceso activo a través del que, a la vez, se desarrollen destrezas y sensibilidades para toda la vida.

Sin embargo, una de las carencias de la educación médica actual radica en la dificultad de 
transmitir habilidades relacionadas con lo humano, con lo afectivo, lo ético o lo moral. Es ese algo que no siempre se encuentra o es fácil obtener de los libros y que tenemos tan cerca como la práctica en la cabecera del paciente, de la mano del compañero médico y maestro.

Termino citando a William Osler, quien en el año 1903, en una conferencia ante sus alumnos sobre 'La palabra clave en medicina' decía: 'Más que ningún otro, el médico puede ilustrar la segunda gran lección, que no estamos aquí para sacar de la vida cuanto más podamos para nosotros mismos, sino para intentar que la vida de los demás sea más feliz. Es imposible que nadie tenga mejores oportunidades para vivir esta lección que las que vosotros vais a disfrutar'. (...) 'La práctica de la medicina es un arte, no un comercio; una vocación, no un negocio; una vocación en la que hay que emplear el corazón igual que la cabeza. Con frecuencia lo mejor de vuestro trabajo no tendrá nada que ver con pociones y polvos, sino con el ejercicio de la influencia del fuerte sobre el débil, del justo sobre el malvado, del prudente sobre el necio...'

Y concluía, 'Se ha hecho mucho, pero mucho queda por hacer; un camino ha sido abierto, y las posibilidades para el desarrollo científico de la medicina parece que no tuvieran límite. Excepto en su aplicación, como médicos generales, no tendréis mucho que ver con esto. Vuestro es un deber más alto y sagrado. No penséis en encender una luz que brille ante los hombres para que puedan ver vuestras buenas obras; al contrario, pertenecéis al gran ejército de trabajadores callados, médicos y sacerdotes, monjas y enfermeras, esparcidos por el mundo, cuyos miembros no disputan ni gritan, ni se oyen sus voces en las calles, sino que ejercen el ministerio del consuelo entre la tristeza, la necesidad y la enfermedad'.

\section{Bibliografía}

1. Encyclopedia of bioethics. New York, 1978, 1995.

2. Kant I. Fundamentación de la metafísica de las costumbres. 2. ${ }^{a}$ ed. Madrid: Espasa-Calpe; 1963.

3. Osler W. La palabra clave en medicina. In: Un estilo de vida. Madrid: Fundación Lilly; 2008. p. 311.

4. Porter R. The greatest benefit to mankind. New York: Norton; 1998. p. 718.

5. Potter VR. Bioethics: the science of survival. Perspect Biol Med 1970; 14: 127-53.

6. Potter VR. Bioethics. Bridge to the future. New Jersey: Prentice-Hall; 1971

7. Savater F. El valor de elegir, Barcelona: Ariel; 2003.

8. Tomás de Aquino. Suma teológica. II-IIa parte, q. 47, art. 1. 